\title{
Reduced folate carrier 1 (RFC1) is associated with cleft of the lip only
}

\author{
A.R. Vieira ${ }^{1,2,3,4}$, M.E. Cooper ${ }^{1,3}$, M.L. Marazita ${ }^{1,3,4,5}$, E.E. Castilla ${ }^{6,7}$ and I.M. Orioli ${ }^{8}$ \\ ${ }^{1}$ Department of Oral Biology, ${ }^{2}$ Department of Pediatric Dentistry, ${ }^{3}$ Center for Craniofacial and Dental \\ Genetics, School of Dental Medicine, University of Pittsburgh, Pittsburgh, PA, USA \\ ${ }^{4}$ Department of Human Genetics, Graduate School of Public Health, University of Pittsburgh, Pittsburgh, \\ PA, USA \\ ${ }^{5}$ Department of Psychiatry, School of Medicine, University of Pittsburgh, Pittsburgh, PA, USA \\ ${ }^{6}$ ECLAMC at Departamento de Genética, Fundação Oswaldo Cruz, Rio de Janeiro, RJ, Brasil \\ ${ }^{7}$ ECLAMC at CEMIC, Buenos Aires, Argentina \\ ${ }^{8}$ ECLAMC at Departamento de Genética, Universidade Federal do Rio de Janeiro, Rio de Janeiro, RJ, \\ Brasil
}

Correspondence to: A.R. Vieira, 614 Salk Hall, Department of Oral Biology, School of Dental Medicine, University of Pittsburgh, 3501 Terrace Street, Pittsburgh PA 15261, USA

Fax: +1-412-624-3080. E-mail: arv11@dental.pitt.edu

\begin{abstract}
In this report, we have reanalyzed genotyping data in a collection of families from South America based on maternal origin. Genotyping analysis was performed at the Craniofacial Anomalies Research Center at the University of lowa. These genotypes were derived from genomic DNA samples obtained from blood spots from children born with isolated orofacial clefts in 45 hospitals located in eight countries (Argentina, Bolivia, Brazil, Chile, Ecuador, Paraguay, Uruguay, and Venezuela) collaborating with ECLAMC (Latin American Collaborative Studies of Congenital Malformations) between January 1998 and December 1999. Dried blood samples were sent by regular mail to the Laboratory of Congenital Malformations, Federal University of Rio de Janeiro. Previous findings suggested that mitochondrial haplotype D is more commonly found among cleft cases born in South America. We hypothesized that association of certain genes may depend upon the ethnic origin, as defined by populationspecific markers. Therefore, we tested if markers in MTHFR (5,10-methylenetetrahydrofolate reductase) and RFC1 (reduced folate carrier 1) were associated with oral clefts, depending on the maternal origin defined by the mitochondrial haplotype. Transmission distortion of alleles in MTHFR C677T and RFC1 G80A polymorphic variants was tested in 200 mother/affected child pairs taking into consideration maternal origin. RFC1 variation was over-transmitted to children born with cleft lip only ( $P$ $=0.017$ ) carrying mitochondrial DNA haplotypes other than haplotype D. Our results provide a new indication that variation in RFC1 may contribute to cleft lip only. Future studies should investigate the association between oral clefts and RFC1 based on more discrete phenotypes.
\end{abstract}

Key words: Cleft lip and palate; Reduced folate carrier 1; 5,10-Methylenetetrahydrofolate reductase; Folate; Oral clefts; Mitochondrial DNA

Research supported in part by NIH/NIDCR grants R01-016148, R21-DE016930, and P50-DE016215.

Received December 13, 2007. Accepted April 15, 2008

\section{Introduction}

Although oral-facial clefts are among the most common congenital defects, their etiology remains largely unknown, with only a few cases associated with identified rare syndromes or secondary to recognized teratogen exposure. Most clefting is non-syndromic (without associated anomalies) and considered secondary to complex gene/gene or gene/environment interactions. We have previously demonstrated that cleft individuals in South America present a higher frequency of Amerindian mitochondrial haplotypes, in particular haplotype D (1). When 
this same population was evaluated for genes related to the folate pathway, no association was found between genetic markers in MTHFR (5,10-methylenetetrahydrofolate reductase) or RFC1 (reduced folate carrier 1) and oral clefts (2). Conflicting results have been published regarding the association between cleft lip and palate and MTHFR (3-13). Lack of association between markers in RFC1 and oral clefts has been consistently reported (14-17). However, one study with Filipino families suggested borderline significant nonparametric LOD score results $(P=0.06)$ for markers in RFC1 (18).

Isolated cleft lip and palate is more common in Asians and Amerindians, intermediate in Caucasians and less

Table 1. Number of cases of cleft lip only $(C L)$ and cleft lip with cleft palate (CLP) according to ECLAMC data from 8 Latin American countries.

\begin{tabular}{lrrrc}
\hline Country & Cases & CL & CLP & Unknown \\
\hline Argentina & 80 & 21 & 58 & 1 \\
Bolivia & 24 & 6 & 17 & 1 \\
Brazil & 27 & 13 & 14 & 0 \\
Chile & 24 & 4 & 18 & 2 \\
Ecuador & 2 & 2 & 0 & 0 \\
Paraguay & 8 & 1 & 6 & 1 \\
Uruguay & 7 & 3 & 4 & 0 \\
Venezuela & 21 & 7 & 12 & 2 \\
Total & 193 & 57 & 129 & 7 \\
\hline
\end{tabular}

Data are reported as number and include 12 cases that were excluded during statistical analysis because they had an underlying syndrome or other major or multiple minor defects, as determined by record review. ECLAMC = Latin American Collaborative Study of Congenital Malformations. Unknown = data not available if patient had only CL or CLP.

Table 2. Specific mtDNA lineage frequencies among patients reported in Table 1.

\begin{tabular}{lcc}
\hline Haplogroups & Number of individuals & Relative frequency \\
\hline African & 4 & 0.022 \\
European & 11 & 0.059 \\
Amerindian & 172 & 0.919 \\
Total & 187 & 1.0 \\
Amerindian subtypes & & \\
A & 13 & 0.08 \\
B & 2 & 0.002 \\
C & 17 & 0.1 \\
D & 140 & 0.818 \\
Total & 172 & 1.0 \\
\hline
\end{tabular}

Differences in the total number of individuals reported here (187) compared to Table 1 (193) are due to the inability to identify mtDNA haplogroups. frequent in Africans and African descents (19). Therefore, we hypothesized that some genes that contribute to clefts may have a stronger effect in a particular ethnic group. Our previous work suggested findings that mitochondrial haplotype $\mathrm{D}$ is more commonly found among cleft cases born in South America. We hypothesized that association for certain genes may depend upon the ethnic origin, as defined by population-specific markers. Therefore, we tested if markers in MTHFR and RFC1 were associated with oral clefts, depending on the maternal origin defined by the mitochondrial haplotype.

\section{Material and Methods}

Samples from this study were drawn from the Latin American Collaborative Study of Congenital Malformations (ECLAMC). ECLAMC has operated since 1967 and utilizes 70 hospitals and volunteer physicians to collect data on approximately 150,000 births per year (4 million since 1967) (20). From January 1998 to June 2000, ECLAMC collected blood spots on filter cards from patients with isolated (non-syndromic) cleft lip with or without cleft palate and their mothers from eight countries in Latin America (Table 1) (21). Samples were obtained after volunteers signed an informed consent form. Patients having a known syndrome or other major or multiple minor defects $(\mathrm{N}=12)$, as determined by record review, were excluded during data analysis. Also excluded from the analysis were the seven patients with cleft type unknown. DNA was extracted from filter card blood spots using modifications of published protocols. Kinetic PCR and molecular beacon assays were performed according to published protocol to test the allelic variants of MTHFR C677T and RFC1 G80A (10).

Cleft lip only and cleft lip with cleft palate cases were evaluated separately and then in combination (cleft lip with or without cleft palate). Mother and proband genotypes were compared to determine the transmitted alleles versus the non-transmitted alleles. The likelihood ratio test (LRT) of Weinberg was applied to detect transmission distortion (22). The major advantage of the LRT over the standard transmission disequilibrium test (23) for parent-child data is that additional pairs are informative (i.e., all mother-child pairs in which the mother is heterozygous), under an assumption that the distribution of paternal alleles is the same as the maternal. Mating types were defined as 0,1 , or 2 indicating none, one, or two copies of the target allele (the more common allele was used as the target allele). This analysis was stratified by mitochondrial haplotype. Table 2 describes the mitochondrial haplotype frequency in the study population. 


\section{Results}

Individuals with mitochondrial DNA haplotype $D$ were analyzed separately from individuals with other mitochondrial DNA haplotypes. For cleft lip only, the results indicated that there was an association between RFC1 and risk of cleft lip only among individuals with mitochondrial DNA haplotype other than haplotype $D(P=0.017$; Table 3$)$. Individuals with mitochondrial DNA haplotype $D$ did not show association with the RFC1 alleles (data not shown). Statistically significant differences between these two groups were assessed by the chi-square test $\left(\chi^{2}=8.680, P=0.003\right)$. There was also no evidence of any difference between the mitochondrial DNA groups regarding MTHFR genotypes.

\section{Discussion}

Indians, Africans, and Europeans form the racial background of the American continent. When Europeans discovered America, the Indian population was spread over the entire continent. Spanish and Portuguese settlers distributed themselves fairly well over today's Mexico, Central and South America, except in the far south and the remote interior. The importation of Africans started by the end of the 1400's and lasted for about 400 years (24). The colonization of the new world by the Europeans initially involved men only, and the immigration of European women during the first centuries was insignificant. Admixture analyses performed in Brazil, Chile and Colombia suggest a historical pattern of directional mating that preferentially involved immigrant men and native women (25-30). The LRT analysis performed assumes that the distribution of paternal alleles was the same as the maternal. Although there is strong data supporting a pattern of directional mating during South America's colonization, available data from the eight countries that contributed samples to our studies demonstrate that frequency of random autosomal alleles in unrelated males and females from these countries was comparable, therefore our approach was valid (31-38).

The reanalysis of the MTHFR data based on maternal origin confirms our previous results in which no association between MTHFR and cleft lip and palate was found (2). On the other hand, it appears that the association between cleft lip only and RFC1 in South Americans re-
Table 3. MTHFR and RFC1 LRT results include only individuals with mtDNA haplotypes other than $\mathrm{D}$. *Difference in the total number of non-haplogroup $D$ individuals compared to Table 2 is due to PCR failure. P values were derived from a chi-square table using $\chi^{2}$ $=-2\left(\mathrm{LnL}_{\text {Model II }}-\mathrm{LnL}_{\text {Model I }}\right)$.

lates to ancestral origin that is independent among individuals with maternal lineage containing the mitochondrial DNA haplotype $D$. The mitochondrial DNA haplotype $D$ is more frequently found among the Aleuts, Amazonian Amerindians, Andean Amerindians, and Patagonian Amerindians. In Asia, it can be seen more frequently in populations living in the north of Mongolia, far North of Russia, and Korea (39). The mitochondrial DNA haplotype D may identify people where genes other than RFC1 are acting in the ECLAMC population that predisposes to cleft lip only or is confounded with environmental factors that serve as risk factors for clefts found more commonly in individuals of Amerindian descent.

There is a marked difference in the population origin of the female and male founders in South America (25-30). The association between cleft lip only and RFC1 in South America may be more easily expressed in individuals carrying mitochondrial DNA Amerindian-specific haplotypes A, B, and/or C and male founders originated in Spain and Portugal.

Although the positive RFC1 association reported here relates to a small subset of the population studied, our results provide a new indication that variation in RFC1 may contribute to cleft lip only. With the exception of our previous report (2), none of the previous studies that investi- 
gated the possible association between oral clefts and variation in RFC1 investigated cleft lip only separately from cleft lip with palate (14-17). Future investigations should consider refining data analysis to explore the existent variation in the clinical expression of oral clefts.

Although the biochemical evidence and clinical trial results are nowhere near being consistent and persuasive for a folate effect on oral clefts as they are for a folate effect on neural tube defects, studies such as ours suggest that mutations in genes involved in the folate pathway exist. The relevance of this finding may be dependent on individuals' specific genetic background, in this case, maternal mitochondrial origin.

The mitochondrial DNA haplogroup $D$ in the South American cleft population may be ideal for performing a

\section{References}

1. Vieira AR, Karras JC, Orioli IM, Castilla EE, Murray JC. Genetic origins in a South American clefting population. Clin Genet 2002; 62: 458-463.

2. Vieira AR, Murray JC, Trembath D, Orioli IM, Castilla EE, Cooper ME, et al. Studies of reduced folate carrier 1 (RFC1) A80G and 5,10-methylenetetrahydrofolate reductase (MTHFR) C677T polymorphisms with neural tube and orofacial cleft defects. Am J Med Genet A 2005; 135: 220-223.

3. Gaspar DA, Pavanello RC, Zatz M, Passos-Bueno MR, Andre M, Steman S, et al. Role of the C677T polymorphism at the MTHFR gene on risk to nonsyndromic cleft lip with/ without cleft palate: results from a case-control study in Brazil. Am J Med Genet 1999; 87: 197-199.

4. Mills JL, Kirke PN, Molloy AM, Burke H, Conley MR, Lee YJ, et al. Methylenetetrahydrofolate reductase thermolabile variant and oral clefts. Am J Med Genet 1999; 86: 71-74.

5. Martinelli M, Scapoli L, Pezzetti F, Carinci F, Carinci P, Stabellini G, et al. C677T variant form at the MTHFR gene and CL/P: a risk factor for mothers? Am J Med Genet 2001; 98: 357-360.

6. Blanton SH, Patel S, Hecht JT, Mulliken JB. MTHFR is not a risk factor in the development of isolated nonsyndromic cleft lip and palate. Am J Med Genet 2002; 110: 404-405.

7. Prescott NJ, Winter RM, Malcolm S. Maternal MTHFR genotype contributes to the risk of non-syndromic cleft lip and palate. J Med Genet 2002; 39: 368-369.

8. Jugessur A, Wilcox AJ, Lie RT, Murray JC, Taylor JA, Ulvik $A$, et al. Exploring the effects of methylenetetrahydrofolate reductase gene variants $\mathrm{C} 677 \mathrm{~T}$ and $\mathrm{A} 1298 \mathrm{C}$ on the risk of orofacial clefts in 261 Norwegian case-parent triads. Am J Epidemiol 2003; 157: 1083-1091.

9. Pezzetti F, Martinelli M, Scapoli L, Carinci F, Palmieri A, Marchesini J, et al. Maternal MTHFR variant forms increase the risk in offspring of isolated nonsyndromic cleft lip with or without cleft palate. Hum Mutat 2004; 24: 104-105.

10. Shi M, Caprau D, Dagle J, Christiansen L, Christensen K, Murray JC. Application of kinetic polymerase chain reaction whole genome linkage disequilibrium screen, because it has theoretically the same 'maternal founder', and might share the same genetic causes of non-syndromic cleft lip and palate. The combination of historical data about population migrations and population-specific DNA variants should be further explored to help understand the heterogeneity underlying non-syndromic cleft lip and palate and other complex traits.

\section{Acknowledgments}

We thank all the families that participated in this project, Jeff Murray for his constant support, and Anne Warrington who provided technical support (Department of Pediatrics, University of lowa). and molecular beacon assays to pooled analyses and highthroughput genotyping for candidate genes. Birth Defects Res A Clin Mol Teratol 2004; 70: 65-74.

11. Zhu J, Ren A, Hao L, Pei L, Liu J, Zhu H, et al. Variable contribution of the MTHFR C677T polymorphism to nonsyndromic cleft lip and palate risk in China. Am J Med Genet A 2006; 140: 551-557.

12. Brandalize AP, Bandinelli E, Borba JB, Felix TM, Roisenberg I, Schuler-Faccini L. Polymorphisms in genes MTHFR, MTR and MTRR are not risk factors for cleft lip/palate in South Brazil. Braz J Med Biol Res 2007; 40: 787-791.

13. Chevrier C, Perret C, Bahuau M, Zhu H, Nelva A, Herman $\mathrm{C}$, et al. Fetal and maternal MTHFR C677T genotype, maternal folate intake and the risk of nonsyndromic oral clefts. Am J Med Genet A 2007; 143: 248-257.

14. Shaw GM, Zhu H, Lammer EJ, Yang W, Finnell RH. Genetic variation of infant reduced folate carrier (A80G) and risk of orofacial and conotruncal heart defects. Am J Epidemiol 2003; 158: 747-752.

15. Pei LJ, Ren AG, Hao L, Zhu HP, Zhu JH, Zhao WR, et al. Study on the association between reduced folate carrier gene polymorphism and congenital heart defects and cleft lip with or without cleft palate. Zhonghua Liu Xing Bing Xue Za Zhi 2004; 25: 1063-1067.

16. Mostowska A, Hozyasz KK, Jagodzinski PP. Maternal MTR genotype contributes to the risk of non-syndromic cleft lip and palate in the Polish population. Clin Genet 2006; 69: 512-517.

17. Pei L, Zhu H, Zhu J, Ren A, Finnell RH, Li Z. Genetic variation of infant reduced folate carrier (A80G) and risk of orofacial defects and congenital heart defects in China. Ann Epidemiol 2006; 16: 352-356.

18. Schultz RE, Cooper ME, Daack-Hirsch S, Shi M, Nepomucena $\mathrm{B}$, Graf KA, et al. Targeted scan of fifteen regions for nonsyndromic cleft lip and palate in Filipino families. $A m \mathrm{~J}$ Med Genet A 2004; 125: 17-22.

19. Mossey PA, Little J. Epidemiology of oral clefts: an interna- 
tional perspective. In: Wyszynski DF (Editor), Cleft lip and palate. From origin to treatment. New York: Oxford University Press; 2002. p 127-158.

20. Castilla EE, Orioli IM. ECLAMC: the Latin-American collaborative study of congenital malformations. Community Genet 2004; 7: 76-94.

21. Vieira AR, Orioli IM, Castilla EE, Cooper ME, Marazita ML, Murray JC. MSX1 and TGFB3 contribute to clefting in South America. J Dent Res 2003; 82: 289-292.

22. Weinberg CR. Allowing for missing parents in genetic studies of case-parent triads. Am J Hum Genet 1999; 64: 11861193.

23. Spielman RS, Ewens WJ. The TDT and other family-based tests for linkage disequilibrium and association. Am J Hum Genet 1996; 59: 983-989.

24. Carlson FA. Geography of Latin America. New York: Prentice Hall, Inc.; 1937.

25. Palomino HM, Palomino H, Cauvi D, Barton SA, Chakraborty R. Facial clefting and Amerindian admixture in populations of Santiago, Chile. Am J Hum Biol 1997; 9: 225-232.

26. Batista dos Santos SE, Rodrigues JD, Ribeiro-dos-Santos AK, Zago MA. Differential contribution of indigenous men and women to the formation of an urban population in the Amazon region as revealed by mtDNA and Y-DNA. Am J Phys Anthropol 1999; 109: 175-180.

27. Alves-Silva J, da Silva Santos M, Guimarães PE, Ferreira AC, Bandelt HJ, Pena SD, et al. The ancestry of Brazilian mtDNA lineages. Am J Hum Genet 2000; 67: 444-461.

28. Carvajal-Carmona LG, Soto ID, Pineda N, Ortiz-Barrientos D, Duque C, Ospina-Duque J, et al. Strong Amerind/white sex bias and a possible Sephardic contribution among the founders of a population in northwest Colombia. Am J Hum Genet 2000; 67: 1287-1295.

29. Mesa NR, Mondragon MC, Soto ID, Parra MV, Duque C, Ortiz-Barrientos D, et al. Autosomal, mtDNA, and Y-chromosome diversity in Amerinds: pre- and post-Columbian patterns of gene flow in South America. Am J Hum Genet
2000; 67: 1277-1286.

30. Carvalho-Silva DR, Santos FR, Rocha J, Pena SD. The phylogeography of Brazilian Y-chromosome lineages. $A m \mathrm{~J}$ Hum Genet 2001; 68: 281-286.

31. Sans M, Alvarez I, Callegari-Jacques SM, Salzano FM. Genetic similarity and mate selection in Uruguay. $J$ Biosoc Sci 1994; 26: 285-289.

32. Gene M, Fuentes M, Huguet E, Pique E, Bert F, Corella A, et al. Quechua Amerindian population characterized by HLA-DQ alpha, YNZ22, 3'APO B, HUMTH01, and HUMVWA31A polymorphisms. J Forensic Sci 1998; 43: 403-405.

33. Figueroa CC, Acuna M, Cifuentes L. Gene frequencies for six STR loci in a Chilean population of mixed ancestry. $J$ Forensic Sci 2000; 45: 742-743.

34. Chiurillo MA, Morales A, Mendes AM, Lander N, Tovar F, Fuentes A, et al. Genetic profiling of a central Venezuelan population using 15 STR markers that may be of forensic importance. Forensic Sci Int 2003; 136: 99-101.

35. Gonzalez-Andrade F, Sanchez D, Martinez-Jarreta B. Genetic profile of the Ecuadorian Mestizo population (EcuadorSouth America) by using the Power Plex 16 System Kit. Forensic Sci Int 2003; 135: 64-66.

36. Martinez-Espin E, Fernandez-Rosado F, Alvarez JC, Entrala C, Lorente JA, Oviedo de DM, et al. Paraguayan population data on the fifteen STR loci included in the PowerPlex 16 kit. J Forensic Sci 2003; 48: 253-255.

37. Martinez MV, Bertoni B, Parra EJ, Bianchi NO. Characterization of admixture in an urban sample from Buenos Aires, Argentina, using uniparentally and biparentally inherited genetic markers. Hum Biol 2004; 76: 543-557.

38. Whittle MR, Romano NL, Negreiros VA. Updated Brazilian genetic data, together with mutation rates, on 19 STR loci, including D10S1237. Forensic Sci Int 2004; 139: 207-210.

39. Schurr TG. Mitochondrial DNA and peopling of the New World. Am Scientist 2000; 88: 246-253. 